\title{
The Confusion of the Symbol and That Which Is Symbolised: Religion, the Nation State, Politics and Society
}

\author{
Richard Startup \\ College of Science, Swansea University, Swansea, UK \\ Email: r.startup@swansea.ac.uk
}

How to cite this paper: Startup, R. (2022). The Confusion of the Symbol and That Which Is Symbolised: Religion, the Nation State, Politics and Society. Open Journal of Philosophy, 12, 54-68.

https://doi.org/10.4236/ojpp.2022.121004

Received: December 19, 2021

Accepted: February 14, 2022

Published: February 17, 2022

Copyright ( 2022 by author(s) and Scientific Research Publishing Inc. This work is licensed under the Creative Commons Attribution International License (CC BY 4.0).

http://creativecommons.org/licenses/by/4.0/

\section{(c) (i) Open Access}

\begin{abstract}
The extent of confusion between symbols and that which is symbolised is examined across five institutional spheres. Religion is the institution most marked by confusion of this type; indeed in some respects the symbolic message of religion may be the extent of the substantive reality. On the other hand, the very existence of the nation state may be judged to depend upon the exercise of the human imagination; hence providing a source of instability which may lead to the excesses of nationalism. In regard to social status, the main problematical element is a certain circularity: it is necessary to get people to exhibit differences in behaviour which are then used to justify or constitute the status differences themselves. In politics, the symbolism of left and right threatens to strangle creative thinking, while in education the tendency on all sides to orient towards public systems of measurement and grading undermines the claim that what is really important is pupil and student learning. A social cost is being paid for the failure to recognise and, where possible, address the issues identified.
\end{abstract}

\section{Keywords}

Symbol and Symbolised, Religious Symbols, Nation and Nationalism, Social Status, Left and Right in Politics, Making the Grade in Education

\section{Introduction}

It is a familiar fact that symbols play a basic role in the meanings and processes central to the functioning of our institutions; indeed, the contribution of symbols—in, for instance, religion, national identity and politics—-may be so taken for granted that it is viewed as being unproblematic. In this connection, the vital nexus, of course, is that between a particular symbol and that which it symbol- 
ises, with the latter typically viewed as the truly essential element. No doubt we use symbols because they are publicly identifiable, often memorable and arrest our attention. Could it be the case, however, that despite the apparent clarity of symbols-or even in some cases because of it-there are problems in institutional life because there is confusion between the symbol and that which is symbolised? Could it even be that this type of confusion is relatively widespread and raises issues and problems that are neglected but need to be addressed?

This exploratory article is directed at these concerns through a consideration of symbolic representations across some of the main institutions of society: religion; the nation state; social status; politics; education. At the outset there is no easy assumption that the way in which the relation between symbol and symbolised works itself out is the same in the differing spheres; almost certainly it does not. Indeed, insights may be gained from comparison across the range. The idea of symbolic representation is familiar enough but what is lacking is systematic examination of the relation between symbol and symbolised, in such a way as to provide society-wide illumination in traditional and modern contexts.

An influential contribution to our understanding of symbolism is that of Sperber (1975). He affirms that the use of symbols in a culture is not accurately described by semiotics. He does not propose a theory of symbolism but has tried, "only to define a framework within which a theory of symbolism may be constructed" (Sperber, 1975: p. 148). In developing his argument he analyses the use of symbolism in both pre-literate and western cultures and provides many insights into symbols and their uses. A key point which he makes which will be well illustrated here is that symbols are used primarily to show group affiliation. Those affiliations may concern the positions of oneself and others, the relation between the two, and the activities and potentialities with which symbolic representations are associated.

\section{Religion}

Confusion may be expected to arise within religion, where there is very extensive use of symbolism. This is for the following reason: that which is named and represented may have no reality over and above the name and representation, or at least its reality may reasonably be doubted.

In respect of the religion of ancient Egypt this type of confusion was at the heart of a very complex system of deities, a system which seems to have been particularly obsessed with death. The modern observer tends to find baffling, "the great number of deities, the variety of forms they take and the complexity of the relationships between them" (Oakes \& Gahlin, 2002: p. 267). As might be expected the stories and myths involving and surrounding the deities were a means of explaining the unknown. The names of gods and goddesses were certainly as important as their characteristics and the means by which they were represented; offerings could only be made to a divine force with its own name. As is well-known the king of Egypt was identified with the God, Horus, often 
represented as a falcon; the ubiquitous symbol of the "Eye of Horus" symbolized healing, wholeness and strength. Isis, the mother goddess, and more specifically mother of Horus and thus of the king, according to the myths about her, could transform herself into any guise she desired. Thus she was manifested in the "Great White Sow of Heliopolos" and the Isis-cow giving birth to the sacred Apis bull of Memphis (Oakes \& Gahlin, 2002: p. 286). In sum, ancient Egyptian religion is particularly marked by its lack of the distinction between the name and the thing named, which we tend to make automatically. "For the ancient Egyptian, the name was the thing; the real object we separate from its designation was identical with it. So might be other images." (Roberts, 1980: p. 89).

An example from Christianity may also help. God is traditionally oriented to as male but he is evidently not male in any sense at all over and above the traditional attribution. The substance of God's male identity resides in such usages as "Our Father" in the Lord's Prayer and "sent His only begotten Son" in the Bible's New Testament. Hence in this instance-as more widely-verbal and pictorial formulae are the substantive reality which tends to gain salience relative to that to which they supposedly refer.

The ritual of the Eucharist illustrates the layers of complexity potentially involved. The practice has been for Roman Catholics and Anglicans (for instance) to understand what is happening differently (Editors of the Encyclopaedia Britannica, 2020). For many Anglicans the wafer and wine symbolise the body and blood of Christ while for Roman Catholics they become the body and blood. At least it may be said, one cannot have it both ways. Prima facie with respect to Roman Catholics there can be said to be this type of confusion: there is orientation towards a symbol as though it were the thing symbolised. This is only a first step, however, for there are further layers of symbolism.

One could get "stuck" at the level of understanding the wafer and wine simply as symbols for the body and blood of Jesus without going further; the further step is to understand the combination in turn as a symbol for His suffering and sacrifice on the cross; again, this last could be taken as a symbol of Him taking upon Himself the burden of saving humanity from sin and making God's grace available to the faithful. So there are in fact several levels at which confusion between symbol and that which is symbolised may arise; and there may be failure to ascend the various levels.

One may take from the Eastern Orthodox form of Christianity a further example where orientation to a symbol may come to predominate over what it symbolises. This is the activity of praying to a saint using an icon. The belief is that the saint looks at the believer through the painted eyes of the saint depicted. Where someone is praying facing an icon of the Virgin Mary, they may confuse the pictorial representation with the Virgin Mary. Perhaps generally they will not do this, but there remains the problem that the reference to the Virgin as existing in the present-or throughout time-tends to make of her no more than an assemblage of what is attributed to her: apart from the assemblage there may be nothing. Hence the reality of the icon gains in relative salience. 
To take a further example, a notion worth scrutinising which was maintained within Roman Catholicism well into the twentieth century may be stated as follows: "The Jews were responsible for the death of Christ/God." Suppose it is taken from the Bible's New Testament that some Jews were involved in the death of the person Jesus. In passing one may note that some scholars believe that identifiable anti-Jewish verses were in fact later additions. Be that as it may, it is reasonable to ask how one can pass from limited specific involvement to saying Jews for evermore are responsible for the death of Christ/God. There does seem to be insistence here that one be accepted as a justificatory and validating symbol for the other.

The same pattern is evident in the creation myth. The Bible's Book of Genesis provides an account of the creation; it goes on to tell us that the original humans disobeyed God and were driven from paradise. The notion of original sin is then built on this. Thus the account is taken as symbolic of our fallen state today (and throughout history) and God's outlook on it. The fallen state today, however, if that is how it may reasonably be characterised, is a separately identifiable state of affairs; but there is a tendency to take it as self-evident and also to tar everyone with the same brush in this respect. Therefore, if, on the basis of Genesis, there is insistence that we are all in a fallen state, then the former is being taken as a validating symbol of the latter: the symbol is taken as descriptively validating that which is symbolised.

On a lighter note, a celebration and festival about which the Christian authorities are aware of confusion is Christmas. Of course it is recognised that December 25th is a conventional rather than an actual birth date for Jesus. It is not infrequently said that during the celebration people insufficiently acknowledge the true meaning of Christmas. Significantly, the latter phrase began to be employed in the mid-nineteenth century when there was a discernible shift to a more secular culture. The phrase was used in Dickens' influential work $A$ Christmas Carol (1843) about an old miser Scrooge who is redeemed following the visit of three ghosts. The way it is often put is to say that people are oriented to gift exchange and enjoyment of a special seasonal holiday rather than celebrating the birth of Christ, perhaps in conjunction with giving to the poor and needy without expectation of return. Additional concerns are raised. It is sometimes said that Christians had simply taken over a pre-existing festival perhaps connected to Old Father Frost and concerned with celebrating the turn of the year and the days getting longer. On the other hand, some Christians would rather there be a full spiritual response to the meaning of the totality of Christ's life on Earth than simply a celebration of his birth: the point being that "Christmas" comes from the Mass of Christ where Christians remember that Jesus was born and then died for us. The meaning of Christmas is hence contested both implicitly and explicitly (Nissenbaum, 1997).

Art, architecture, music and ceremony are central to the symbolic structure of religion. As regards Christianity, the story-telling of stained glass was vital at former times of lower literacy; also when services were in Latin rather than the 
vernacular. In respect of pictorial representation, the placing of figures higher and lower and of relative sizes is important; so too is the relative placing of elements of heaven and hell. Everyone is left with the idea that the heavens are "up there" and purgatory and hell are "down there". The symbolic use of the vertical dimension is clear, but what precisely it symbolises is less clear. It rather leaves one asking whether there is a "cosmic" vertical dimension.

\section{National Identity}

In respect of identification with large groups, national identity sits alongside religious identity in its importance in recent centuries. By national identity one means a sense of belonging to a state or nation. While belonging may very much concern one's legal citizenship status, also involved are subjective feelings understood to be shared with a group of people about a large political entity i.e. there is an awareness of similarity and difference and a recognition of "we" and "they". In connection with a nation and nationalism there are indeed many aspects to consider e.g. the self-concept of a group of people; their voluntary participation; their territorial location; the possible sharing of a language; the possession of distinctive values; their common history and where appropriate common "mission" (as in the shared understanding of Israel as a Jewish national home) (Gilbert, 2018). Given that very large populations are typically involved, plainly symbols must mediate between the individual and the large group: national symbols such as the flag, institutions such as the monarchy as well as shared cultural and historical elements and artefacts, are often focused within a context of shared language. Hence it is of the essence that the symbols are employed to express a specific group affiliation.

Putting the position in this way rather dramatises the fact that social-psychological processes are central to the reality and functioning of the nation state. The position is put even more strikingly by Anderson (1983) who refers to nations as "imagined communities". Anderson introduced this key idea when considering the early modern period in Europe and when arguing that, in a context of greater literacy, the nation or state became focal because national sovereignty became a symbol of freedom from traditional religious practices; a key feature was the creation of boundaries defining who was in and who was out (see also Jensen, 2016). Although his account is in some respects contested by Gellner (1983), Anderson's key idea has been taken up and used more widely in relation to both nationalism and nation state formation as well as the more routine functioning of nation states.

What is striking is the very suggestion that the reality and functioning of the nation state could be bound up with the content of the human imagination; yet such appears to be the case. A central concern here is that what is imagined may or may not be the case; also, in conventional terms, it may have desirable or undesirable consequences. Of course, one is mainly concerned with the structuring of imaginative thinking within a large population, rather than the idiosyncratic 
thinking of individual citizens. The 2020 presidential election in the USA provides a contemporary example. We can all imagine that the result of an election could be fixed in advance or decided by fraud-after all, we are familiar enough with that practice in non-democratic regimes. It is another thing entirely, however, for what we can readily imagine to be deemed to have actually occurred within a democracy; yet, following an election conducted in the most routine, straightforward, law-abiding way, perhaps upwards of a third of the American electorate confuse what can be imagined with reality. No doubt this state of affairs was substantially brought about by utterances and tweets of President Trump, but what that illustrates is that confusion results when an individual occupying a position symbolising national unity-the Head of State-acts in a misleading, purely partisan and divisive way.

That the orientation to symbols can come to have a life of its own, is illustrated by the excesses of nationalism in the twentieth century. As one might expect, in a totalitarian state this occurs at all levels. In Nazi Germany "Heil Hitler" replaced the greeting of "Good Morning", while the fact that there were some important Jewish owned businesses came for many to symbolise the idea that Germany was succumbing to a Jewish conspiracy. Altogether more benign in the verdict of history are examples from British wartime experience: the notion that Churchill embodied the British bulldog spirit; that because a bomb had fallen on a royal palace, the British royal family could "look the east end [of London] in the face"; also, the defeat and evacuation at Dunkirk was a form of divine deliverance, a triumph rather than a disaster, with the "Dunkirk Spirit" and the "Dunkirk little ships" becoming part of the nation's folklore.

Political leadership has both instrumental and expressive aspects, which is relevant both in the case of extreme nationalism and the more routine functioning of a nation state. Where there is a constitutional monarchy as in the UK, it is a unifying symbol and it may also be expected to be exemplary; thus before the war divorce was a near-impossibility for anyone closely connected to the throne and especially for the monarch who was designated "defender of the faith" (i.e. the Church of England). More recently, divorces among the Queen's children have implicitly and unintentionally come to symbolise the great changes in British family life. An important recent phenomenon is the way members of the Royal Family can become "semi-detached" but symbolically important—as with Princess Diana becoming "a queen of hearts", "a woman in her own right" and exemplifying "touchy-feely" tendencies; she thereby provided symbolic input to a developing "feminist agenda".

In respect of national identity and nationalism, language is vital since it is a condition for maximally having a sense of "we" as against "they". Two elements are typically linked in people's minds: the national area (which may be a subject of dispute) and the national language which is understood to be associated with it. This last link is typically understood and legitimated historically. Thus within the UK, English is the national language but Welsh is presented as "the language of Wales" even though it is used less than English within the boundary of Wales. 
The net result is that effectively it is not just people who have "rights" but seemingly so has the language itself: the right to exist and for its use to be extended throughout its national area. Hence that which is being symbolised takes on an almost metaphysical character.

\section{Social Status}

In turning next to focus on social status, it can be noted that a key process becomes evident from consideration of rigid ascribed stratification systems; that process may then be seen to operate in more mild ways elsewhere.

Confusion between symbol and what is symbolised is evident in the Hindu caste system of India. Traditionally, caste was all-embracing in its implications, dictating occupation, dietary habits and the interaction with other castes. While there were a great many castes and subcastes, the basic framework or varna was: Brahmins-priests; Kshatryas-warriors and rulers; Vaishyas-farmers, traders and merchants; Shudras-labourers. Outside of the primary system were the Untouchables, who had almost no rights in the society. A key point to notice is that the people who worked in ignominious, polluting and unclean occupations were seen as polluting people and were therefore considered as untouchables (Fowler, 1997). The Untouchables were not allowed to touch people from the four main categories, nor allowed to enter their homes or temples. The character of people's activities is thus confused with their nature, with the notion of pollution applying to both (Olivelle, 2008). Similarly Brahmins would be understood to be people who embodied the admirable qualities of the priest: the character of activities is taken as the character of the status occupant. Hence the symbolic elements order the population in terms of group affiliation.

The same kind of process is evident in other rigid stratification systems. When thinking today about slavery there is often emphasis on the point that a dominant group deprived others of their rights and forced them to work in dreadful conditions, as with plantation slavery. However, this can miss the point that onlookers would have tended to judge slaves by their work, conduct and appearance; to the dominant group (and sometimes to themselves) the slaves were seen to behave in what were considered inferior ways and were therefore inferior people; that was all of which they were capable. Thus observation of what slaves did was taken as indicative of what they were. It is worth noting that as perceptive a philosopher as Aristotle saw slaves and women as naturally inferiorthrough his observation of them. Meanwhile the slave owners could be credited with being superior, cultivated, literate people because they had the leisure time in which to pursue these types of activities (Morgan, 2007; Walvin, 2001).

A somewhat more fluid class system existed in Victorian Britain but the same type of point arises in relation to it. "Cultivated British gentlemen" were politically dominant but why were the rest of the population generally so compliant? The reason is that others felt that upper class gentlemen exhibited in appearance and behaviour that which was felt to fit them for a leadership role. They were 
obviously "educated people" because they dressed in frock coats, had public school accents, read The Times newspaper and knew Latin and Greek. The man who swept horse manure from the road to make a path for his social betters for a few coppers was not similarly looked up to; plainly he was incapable of leadership! Within the discipline of sociology, the term cultural capital has been used to refer to the cultural assets of a person-such as esoteric knowledge acquired at fee-paying schools and high status universities, style of speech and dress-which sustain high position or promote social mobility within a stratified society (Bourdieu \& Passeron, 1990; Bourdieu, 2002; Barker, 2004). In Victorian Britain the possession of cultural capital played a key role in legitimating the position of those in the governing class.

In a modern democratic society thankfully the situation is somewhat more fluid. In the UK there is still a titled upper class but more varied social currents at lower levels. One idea is that people gain status by engaging in "conspicuous consumption", but it is a little unclear whether they are acting intentionally to do this or not; so too is it unclear who in the "audience" is responding and in what way (Veblen, [1899] 2005; Fine, 1994). It continues to be the case that those doing "dirty jobs" tend to have lower status. Where skills or behaviour are esoteric and mysterious this can often be given a higher status meaning-as with barristers.

Confidence in the significance of status symbols tends to diminish where people gain familiarity with differences in time and place; a scarcity factor may also operate. For example, before the invention of the printing press, possession of a large collection of laboriously hand-copied books was a symbol of wealth and scholarship, but in later centuries books and literacy became more widespread. Again, owning the latest technologically-advanced piece of gadgetry may gain one status-for a time. In the Elizabethan period, in a cool country with little strong sunshine, for a woman to have a pale skin-a sign she did not work in the fields-would indicate higher status, but nowadays kudos might be gained from a suntan, indicating possession of the disposable income to travel abroad. Where warriors are respected, a scar can represent honour or courage.

\section{Politics}

One cannot understand modern democratic politics without analysing the way in which symbolism sometimes takes over from substance. In this regard the notion that there is a left-right spectrum or continuum of political positions is basic. It seems that the terms "left" and "right" have their origins in the seating arrangements of the French National and Legislative Assemblies following the commencement of the French Revolution in 1789. Gradually, through the revolutionary period and through subsequent political episodes of the nineteenth century, the meaning of the terms detached itself from its descriptive origins and became ideological in nature (Gauchet, 1996). Crucially, it was exported from France-rather in the way that other elements of the modernist "political agenda" 
were exported from revolutionary France-so that those engaged in politics elsewhere started using the terms in a similar way; and, strikingly, that usage continues to the present day. Given that much political language is primarily being used to persuade, notions connected to the left-right continuum are charged with all manner of meanings of an evaluative and emotional type, which may be directed by political parties towards sections of the electorate to whom they may be expected to appeal.

Given that it is single-dimensional, the left-right continuum gives rise to, or fortifies, the potentially misleading idea that certain political positions or parties are closer to, or more distant from, others. Thus during the cold war period, it was unhelpful to left of centre, democratic socialist parties that they might be seen as being, or represented as, closer to the communist party (even including that of the USSR itself) than they were to their main right of centre, conservative opponents. The point here is that support for democratic institutions as such is an absolutely vital element drawing some parties together and away from others, but it does not lend itself to being mapped onto the left-right continuum. Sometimes, however, that continuum has purportedly been extended round at each end into something more circular so as to be supportive of the claim that extreme-left and extreme-right are close. That way of understanding politics threatens, though, rather to bracket out all manner of ways these types of parties differ among themselves. On all sides, there may be an easy-or lazy—familiarity with the terms even though they fail to apply appropriately in changed circumstances. In a related way commentators are led to offer a critique which sees modern party political conflicts as the product of party systems established in the last century or so, with lines of cleavage "frozen" in time (Boaz, 2008; Ware, 1996). Evidently, the left-right symbolism continues to structure group affiliation but it gives rise to an excessive degree of rigidity in the overall system of affiliation.

The issues were effectively dramatised in the period when the political philosophy of "The Third Way" came to prominence, where an attempt was made across several countries to reorient politics (Giddens, 2008, 2010). A proponent was President Bill Clinton of the USA and the approach was particularly influential during Tony Blair's premiership of the UK from 1997 to 2007. Tony Blair himself identified a main cleavage in politics as, not left against right, but open against closed. In these terms "open" voters tend to be socially liberal, multicultural and in favour of globalisation, while "closed" ones are culturally conservative, oppose immigration and favour protectionism. A central "Third Way" theme is conveyed by the title of a major work by an influential author, the sociologist Giddens (2007), Beyond Left and Right, the Future of Radical Politics, the notion being that a fresh synthesis could be achieved perhaps combining some elements of the right or centre-right with elements of the left or centre-left as well as elements not belonging on that continuum. Some elements of tradition were to be retained but state socialism was rejected in favour of an ethical approach oriented to welfare; rather than the abolition of capitalism there was a need for a 
"new" capitalism perhaps together with the promotion of public-private partnerships; greater equality would be achieved through action to widen the distribution of skills and productive endowments; personal responsibility was to be stressed alongside support for social and economic aspiration. The protection of the environment was taken up, an important issue but one not neatly allocated a position on the left-right continuum.

This was undoubtedly a fertile and potentially highly productive approach; indeed it enjoyed important successes for a time. What, however, it seems it did not do was get people and parties to break free from the limitations of a mind set oriented around the left-right political continuum: it is doubtful indeed whether future politics was set on a new path, "beyond left and right". One can see this because in the major countries concerned, following the period of Third Way politics, there was something of a reversion to conventional left-right politics. For instance, only twelve years after Tony Blair's premiership, the British Labour Party unsuccessfully offered what was agreed on all sides to be a set of conventionally left-wing policies to the country at the 2019 general election. Meanwhile one of the main developments in the USA was the presentation by the Republican party of right-wing policies within a heavily populist setting, particularly in the person of Donald Trump. In terms of outcomes U.S. presidential politics tended to continue to conform to the pattern identified by commentators whereby a left versus right contest tends to be won by the right, but a centre versus right battle might well be won by the centre. Turning to France, the country which gave rise to the imagery of left and right, Emanuel Macron emerged victorious from a presidential contest with five major contenders, characterised on all sides as far-left, moderate-left, centre, moderate-right and far-right (Elgie, 2018). It is not infrequently claimed that contemporary French politics continues to be shaped by the experience and line-up of the French Revolution.

It is important to be clear what is and is not established by the evidence of this section. There is no intention here to claim that everything implied by the left-right continuum is or should be redundant in modern politics. For instance, capitalism continues to generate conflicts of interest: through extended time it continues to create inequalities of wealth and income which some are bound to attack while others defend. No, the key point is that the image of the singledimensional left-right continuum captures and structures thought so that people continue to struggle, often ineffectually, to apply its labels in changed circumstances and in the face of multi-dimensional complexity. At this time within the British Labour party policies meet with approval when the label "socialism" is applied to them, while the same label is applied in the USA primarily to repel people; hence confusion between favouring policies or a label. The Third Way was a significant attempt to structure thinking in new ways to grapple with complexity but it proved only partially successful. So many issues of the present time-such as climate change and ecological problems-require new thinking and approaches. There is a paramount need to transcend the symbolism of left and right, but while that symbolism purports to address the substance of politics, 
it threatens to strangle its creative life.

\section{Education}

In proceeding to consider the institution of education, considerations to do with public measurability must again be highlighted. The purpose of formal education is to convey knowledge and understanding but the key point for present purposes is that education is an extended process with many stages and is centrally bound up with social mobility. One's own knowledge and understanding may be primarily of individual significance but in our kind of society-oriented towards achievement-it must have an important public and recordable dimension for it to play its part in occupational placement and social advancement.

Children in school and students in university are encouraged to learn but, especially when they get older, all the evidence is that they become oriented to performance in standardised objective tests and to obtaining qualifications (Becker, Geer, \& Hughes, 2017; The Graide Network, 2018; O’Meara, 2007). Through their own actions and responses teachers and lecturers encourage them in this respect, despite there being an ideology that education is valuable in and for itself. Teachers and lecturers are substantially oriented on the pupils' behalf, but their concern goes beyond that since they themselves are typically judged by reference to pupil and student objective performance. Meanwhile head teachers and principals may be oriented to how their institutions are placed in local or even national league tables. Notable too is the fact that over the decades there has been more and more concern with objectively measuring the progress of younger children as they pass through various defined stages. Again, despite an ideology focusing on individual educational growth, the whole point about the system is that supposedly objective achievement is recorded; hence there is a basic competitive element. Pupils and students are acquiring qualifications; the significance of this acquisition, however, takes on a life of its own, over and above that of the underlying knowledge.

Relevant too are status hierarchies involving different syllabuses, curricula, schools and colleges. Under the UK's tripartite system of secondary education, grammar schools were ranked higher than secondary technical and secondary modern schools, and all of these ranked lower than fee-paying "public schools"; later, secondary comprehensives took up a position somewhat lower than grammar schools. Among universities Oxford and Cambridge rank highest, then other universities in the research-oriented "Russell Group", then a larger, remaining number among whom there are further distinctions. There has also been a persistent tendency in the UK to rate the pursuance of pure scientific courses above those devoted to applications and engineering. As implied earlier, studying Latin and Greek was at one time the hallmark of a highly educated person but it is a declining asset today.

Plainly all this has to do with progressing and allocating young people to an adult occupational division of labour in a context where achievement is stressed 
and where rewards in terms of money and social status are variable; qualifications are used to permit progress between stages and to make the allocation to occupational positions. The terms "career" and "job", and "professional employment" and "non-professional employment" illustrate vocabulary with status and reward implications. Now, against the emphasis so far, it may be objected that educational qualifications merely record advances in learning and understanding potentially relevant to occupational performance. However, they do not function simply in that kind of way. Whenever someone is appointed to a position because they have a particular qualification, it remains to be seen how much of the associated learning is subsequently used. A further key point is that once a qualification is obtained it is typically retained for ever regardless of whether the underlying knowledge degrades or is lost; a graduate is a graduate for ever, however rusty their knowledge of a particular degree subject may become. In sum, objective tests and qualifications may be said to record or represent educational advance or achievement, but it is orientation towards the record or representation itself which counts for many centrally important societal processes.

\section{Conclusion}

When this topic is raised a widespread reaction is to say that what matters is not so much symbols but what they represent: symbols are in themselves relatively insignificant but what they stand for is of great, even profound, importance. This may be said to be part of the ideology of symbolism but it is seriously misleading in respect of substantive reality. Symbols and that which is symbolised have been considered across a variety of institutional areas and the assertion being made is that they can become confused, even hopelessly confused; indeed the orientation towards the symbol may even supplant what is expected to be the orientation to the symbolised. The symbols have the advantage of being clear-cut and publicly identifiable; sometimes also of being measurable. On the other hand, what is symbolised is altogether more shadowy, more transitory, or more unfathomably complex; indeed in some cases-but perhaps particularly in respect of religionone can even be left wondering whether it exists at all. It is not too much to claim that the structure of symbols anchors social life as we know it; however important that which is symbolised is claimed to be, it simply does not play a comparable role.

The institutional sphere marked by the greatest elaboration of symbolism is religion-particularly when account is taken of its massive historical sweep. It must be stressed that what is said above takes as given the historical evidence of the existence of Jesus and of Christianity in an institutional sense. However, attention and comment is here drawn towards various meanings and practices of the Christian religion through extended time and into the present: the ritual of the Eucharist; prayer using an icon; the notion that the Jews were responsible for the death of Christ; the idea of original sin; the meaning of Christmas; patterns in pictorial representation. It is suggested that the confusion between symbol 
and that which is symbolised arises in these areas. There is also the uncomfortable thought that in these respects the symbolic message of religion may be the extent of the substantive reality.

With regard to the nation state and nationalism, the notion of unifying symbols is familiar enough, but what can come as more of a surprise is the way the whole edifice seems to depend to an important extent upon the foundation of the human imagination; this has to do with the gulf between symbol and its supposed target. An underlying difficulty is for a person to identify with an area on a map and a population in millions, when only a minute fraction of each has been experienced first-hand. The gulf gives rise to sources of instability: the whole may "fly off" towards the excesses of nationalism. There is scope for conspiracy theories such as that promulgated by President Trump.

There is an essential tension between the very idea of social status (on a vertical dimension) and the fact that we are all people-with more in common than we have differences. The consequence is that to justify status differences it is generally necessary to get people to exhibit differences in terms of appearance and behaviour which may then be used, implicitly or explicitly, to justify or constitute the status differences. Thus differential possession of what has been termed cultural capital typically plays an important legitimising role within a society. The symbolically important appearance and behaviour differences have the advantage that they are concrete and observable while the social status which they are taken to signify tends towards the intangible and nebulous. Given comparative evidence, the downplaying of status differences is desirable on utilitarian grounds.

The agenda of politics is complex and changing through time, with pandemic disease and climate change now at the forefront. Yet the notion that there is a single dimensional left-right continuum continues to structure thinking in the democracies perhaps more than any other orienting idea. This way of thinkingor symbolic imagery - has its origins in the upheavals of the French Revolution but it is doubtful whether it does justice to the modern political agenda. The issue of economic inequality within and beyond individual nation states most certainly needs addressing, but a whole number of other basic concerns has arisen in recent decades. "Left-of-centre" and "right-of-centre" continue to be significant as identities and sources of party political affiliation but are ill-suited to a rapidly developing modern political agenda. That pattern of symbolic thought threatens to stifle or strangle creative political thinking when it is most needed.

A common view is that education is all about teaching and learning and it has been characterised as "a slow maturing process" but the tendency is for teachers, pupils and students to orient towards public systems of measurement. These instruments are recognised to be pretty imperfect when used at a particular time and place, but they structure educational and occupational careers for a lifetime-and there is "no going back" in the sense that once a qualification is achieved it continues to be recognised regardless of how much curricular content is subsequently forgotten. In ideological terms, what is learnt or understood 
is all-important and measurement of it is secondary, but measurement and qualifications become primary in the structuring of careers.

Centrally important social institutions have been considered. Where there is an identifiable pattern of symbolic representation it is constantly asserted that what matters is not the symbol but that which it symbolises. If that is so, something is seriously wrong, because in the important instances identified here, there is evidently confusion between the two. Sometimes symbols are mistaken for what they symbolise; sometimes the two compete for attention; in various ways behaviour is redirected or even misdirected. Because symbols are relatively simple, clear-cut and publicly identifiable they have an in-built advantage over the more abstract or complex notions to which they refer. In a sense, symbols may sometimes be judged to have "taken over" and to enjoy a life of their own, as with the left-right continuum in democratic politics. A social cost is being paid, however, where there is failure to recognise and address the problem of confusion between symbols and that which they symbolise.

\section{Conflicts of Interest}

The author declares no conflicts of interest regarding the publication of this paper.

\section{References}

Anderson, B. (1983). Imagined Communities. Verso.

Barker, C. (2004). Cultural Capital. In The Sage Dictionary of Cultural Studies (p. 37). Sage Publications. https://doi.org/10.4135/9781446221280.n47

Becker, H., Geer, B., \& Hughes, E. C. (2017). Making the Grade: The Academic Side of College Life. Routledge. https://doi.org/10.4324/9780203786635

Boaz, D. (2008). The Politics of Freedom: Taking on the Left, the Right, and Threats to Our Liberties. Cato Institute.

Bourdieu, P. (2002). The Forms of Capital. In J. G. Richardson (Ed.), Handbook for Theory and Research for the Sociology of Education (pp. 241-258). Greenwood. https://doi.org/10.1002/9780470755679.ch15

Bourdieu, P., \& Passeron, J. C. (1990). Reproduction in Education, Society and Culture. Sage Publications.

Editors of the Encyclopaedia Britannica (2020). Eucharist: Christianity. https://www.britannica.com/topic/Eucharist

Elgie, R. (2018). The Election of Emmanuel Macron and the New French Party System: A Return to the Éternel Marais? Modern \& Contemporary France, 26, 15-29. https://doi.org/10.1080/09639489.2017.1408062

Fine, G. A. (1994). The Social Construction of Style: Thorstein Veblen's “The Theory of the Leisure Class" as Contested Text. The Sociological Quarterly, 35, 457-472. https://doi.org/10.1111/j.1533-8525.1994.tb01739.x

Fowler, J. (1997). Hinduism Beliefs \& Practices. Sussex Academic Press.

Gauchet, M. (1996). Right and Left. In P. Nora, \& L. D. Kritzman (Eds.), Realms of Memory: The Construction of the French Past, Volume 1. Conflicts and Divisions (pp. 242245). Columbia University Press. 
Gellner, E. (1983). Nations and Nationalism (pp. 6-7). Cornell University Press.

Giddens, A. (2007). Beyond Left and Right: The Future of Radical Politics. Polity Press.

Giddens, A. (2008). The Third Way: The Renewal of Social Democracy. Polity Press.

Giddens, A. (2010). The Third Way and Its Critics: Sequel to "The Third Way" Paperback. Polity Press.

Gilbert, P. (2018). The Philosophy of Nationalism. Routledge. https://doi.org/10.4324/9780429496011

Jensen, L. (2016). The Roots of Nationalism: National Identity Formation in Early Modern Europe, 1600-1815. Amsterdam University Press. https://doi.org/10.5117/9789462981072

Morgan, K. (2007). Slavery and the British Empire: From Africa to America. Oxford University Press.

Nissenbaum, S. (1997). The Battle for Christmas. Blackwell.

O'Meara, K. A. (2007). Striving for What? Exploring the Pursuit of Prestige. In J. C. Smart (Ed.), Higher Education: Handbook of Theory and Research (p. 22). Springer.

Oakes, L., \& Gahlin, L. (2002). Ancient Egypt: An Illustrated Reference to the Myths, Religions, Pyramids and Temples of the Land of the Pharaohs. Hermes House.

Olivelle, P. (2008). Chapter 9. Caste and Purity. In Collected Essays (pp. 240-241). Firenze University Press.

Roberts, J. (1980). The Pelican History of the World. Penguin.

Sperber, D. (1975). Rethinking Symbolism (Translated Alice L. Morton). Cambridge University Press.

The Graide Network (2018). Grades vs Learning: Shifting Attention to What's Important. Teacher Resources.

https://www.thegraidenetwork.com/blog-all/2018/8/1/retiring-the-red-pen-shifting-att ention-from-grades-to-learning

Veblen, T. (1899, 2005). The Theory of the Leisure Class: An Economic Study in the Evolution of Institutions. Elibron Classics.

Walvin, J. (2001). Black Ivory: Slavery in the British Empire. Blackwell.

Ware, A. (1996). Political Parties and Party Systems. Oxford University Press. 